\title{
Striated abrasions from a knife with non-serrated blade-identification of the instrument of crime on the basis of an experiment with material evidence
}

\author{
Michał Kaliszan • Karol Karnecki • Ramazan Akçan • \\ Zbigniew Jankowski
}

Received: 11 February 2011 / Accepted: 13 May 2011 / Published online: 24 May 2011

(C) The Author(s) 2011. This article is published with open access at Springerlink.com

\begin{abstract}
This paper presents an experiment with a knife seized as material evidence in a homicide case. The reason for the experiment was the necessity to determine whether the injuries of the deceased could have been inflicted with this instrument since in the course of the investigation doubt arose as to the origin of linear, parallel scratches around one of the wounds and on the abdominal integuments suggesting a serrated blade. The knife found near the crime scene had a smooth blade and small serrations only on the borderline between its blade and hilt. However, the performed experiment showed that if the knife is directed towards the integuments of the body in a special way, its serrations, even though not located on the blade itself, may leave such striated marks on the body, as those found during the autopsy, suggesting their origin from a serrated blade.
\end{abstract}

Keywords Homicide - Stab wound - Serrated blade . Instrument of crime $\cdot$ Material evidence $\cdot$ Experiment

\section{Introduction}

The forensic pathologist's task often consists of assisting the prosecuting and judicial authorities in determining whether the wounds sustained by the victim of the crime could have

M. Kaliszan $(\bowtie) \cdot$ K. Karnecki $\cdot$ Z. Jankowski

Department of Forensic Medicine, Medical University of Gdańsk, ul. Dębowa 23,

80-204 Gdańsk, Poland

e-mail: michalkal@gumed.edu.pl

R. Akçan

Department of Forensic Medicine,

Hacettepe University School of Medicine,

Sihhiye 06170 Ankara, Turkey been inflicted with the instrument seized as material evidence. For this purpose, a careful inspection of bodily injuries and the alleged instrument used to inflict them must be conducted. The purpose of the examination is to search for characteristic features of the injuries which can be linked to the instrument. While examining the seized instrument, it is important to perform detailed descriptions and measurements of its parts such as the blade, hilt, and other characteristic elements such as projections or serrations. Sometimes, in order to define the marks left by a particular instrument, i.e., in case of sharp, blunt, or gunshot wounds, it is helpful to perform an experiment using that instrument [1-9]. Although, in the case of sharp force traumas, it is possible to differentiate between injuries in bones or cartilages caused with serrated and non-serrated instruments (i.e., knives), the differentiation of the instrument in case of injuries to the skin and soft tissue is much more difficult $[10,11]$. However, in some cases, conducting an experiment can make it possible to confirm or exclude the use of the examined instrument and avoid misidentification of an injury's origin [12]. In the case described in this paper, doubt arose as to whether the injuries found on the body of the deceased could have been caused by the knife discovered near the crime scene.

\section{Case description}

The case concerns an incident during which a dozen or so attackers assaulted a man (XY) who died as a result of the injuries sustained. The autopsy demonstrated that the cause of his death was exsanguination due to a massive hemorrhage as a result of numerous stab wounds to the chest and abdomen and damage to internal organs (the heart, lungs, aorta, liver, and small intestine) within the wound channels. The character, extent, and location of the 
wounds indicated that they had been inflicted with great force, using a sharp instrument.

During the investigation, after a thorough search of the vicinity of the scene of the crime and with the help of recordings of the surrounding area by municipal video surveillance, a knife was found at the bottom of a small nearby pond. In the course of a subsequent police investigation it was established that the knife belonged to one of the assailants.

The post-mortem showed linear, regular, striated scratches on the integuments of the victim's abdomen, and also in the edge of one of the wounds, suggesting that the instrument used to inflict the wounds could have a serrated blade, while the knife found had a smooth one. As a consequence, this led to doubts whether the knife in question was the only instrument of crime or another knife, with a serrated blade, was used too. In view of the above, the public prosecutor examining the case ordered to carry out an experiment to verify whether it was possible to inflict injuries such as those found during the autopsy of the murder victim with the knife found in the pond.

\section{Materials and methods}

The seized material evidence, provided by the public prosecutor, to be used in the experiment was a knife with a metal blade containing the inscription "storm spain" and a metal hilt with plastic elements attached to it. The total length of the knife was $28 \mathrm{~cm}$, of which the blade was $14 \mathrm{~cm}$ and the hilt was $14 \mathrm{~cm}$ long. The maximum width of the blade at the hilt was $4 \mathrm{~cm}$, narrowing to the front and attaining a width of $3 \mathrm{~cm}$ at $5 \mathrm{~cm}$ from the tip of the blade, and then it clearly narrowed forming a sharp ending. On the upper and lower edges of the knife, at the borderline with the hilt, there were single arched depressions with an arch $2.5 \mathrm{~cm}$ long each. The

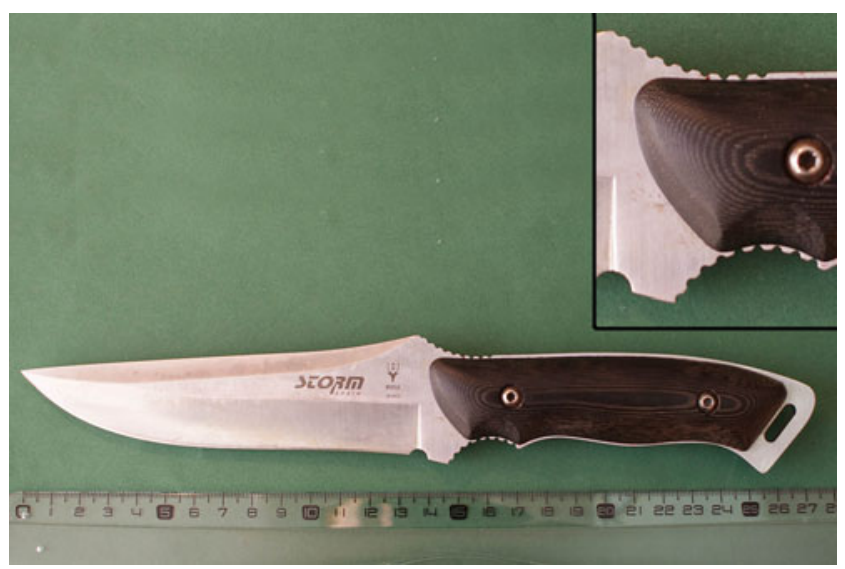

Fig. 1 The knife seized as material evidence. A blow-up of the serrated area of the hilt in the upper right hand corner

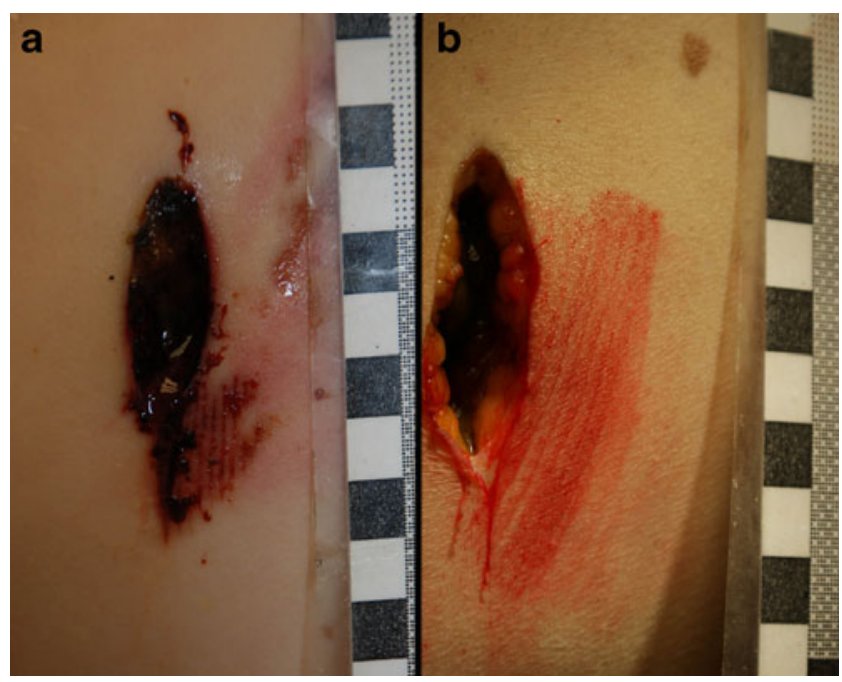

Fig. 2 The wound found during the autopsy (a) and the one inflicted with the knife seized as material evidence (b). In the edges of both wounds there are characteristic scratches looking alike

arched depression in the upper edge had a chord of $2.4 \mathrm{~cm}$ and a height of $0.3 \mathrm{~cm}$, and the one in the lower edge (on the blade side) had a chord of $2.2 \mathrm{~cm}$ and a height of $0.6 \mathrm{~cm}$. The dorsal surface of both depressions was regularly serrated - with nine slightly squared off serrations, each serration approximately $0.1 \mathrm{~cm}$ wide at the top, $0.2 \mathrm{~cm}$ apart from one another (Fig. 1).

At the public prosecutor's order, an experiment was conducted to check whether it was possible to make the characteristic linear abrasions on the skin near the sharp edge of the wound found during the autopsy of XY's corpse (Fig. 2a), and a linearly shaped abrasion of the skin unrelated to these wounds (Fig. 3a), by using the knife

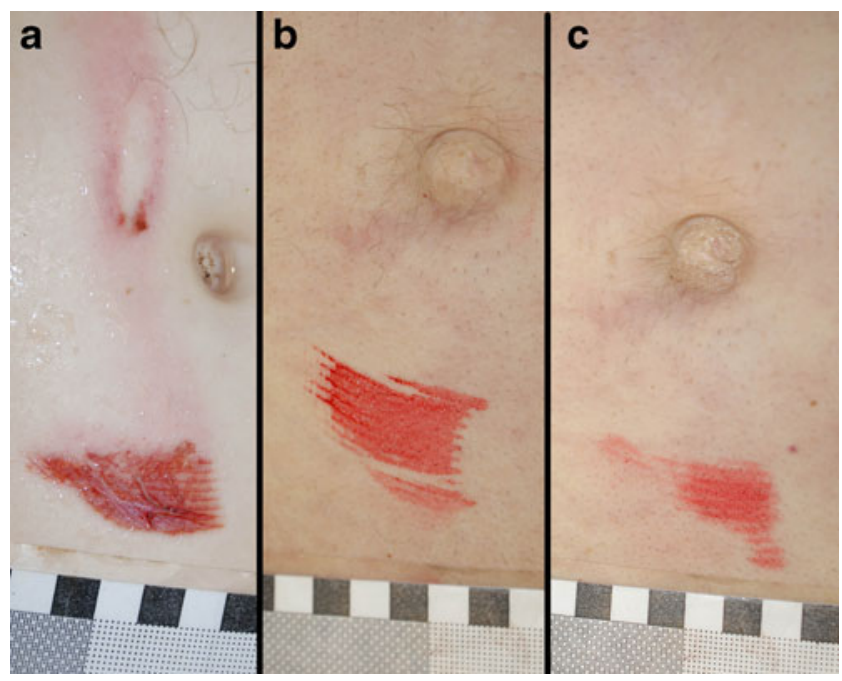

Fig. 3 A characteristic striated abrasion of the skin of the abdomen, near navel, found during the autopsy (a) and marks originated during the experiment with the knife seized as material evidence made by the serrated area of the upper (b) and lower (c) edge of the hilt 
found at the scene of the crime. After the public prosecutor's consent had been given, the experiment was conducted on the body of a person who had died suddenly of natural causes, routinely directed by the Prosecutor's Office to the Department of Forensic Medicine for autopsy. Such an experiment was the only possible way to imitate the real conditions of inflicting the characteristic injuries, as no other simulant material has properties similar enough to human skin, which could be valid in court [13].

During the experiment, red ink was applied onto the abovementioned serrations of the knife then the blade was plunged into the abdominal integuments up to the hilt and then turned left around its long axis and pushed deeper into the body, pressing the lower edge of the knife against the abdominal integuments. The effect seen in Fig. 2b was achieved. Moreover, the knife, plunged into the abdominal integuments up to the hilt with the red ink successively applied onto the serrations, was turned several times in different directions pressing its upper edge against the abdominal integuments, without the effect similar to the abrasion found during the autopsy of XY.

Subsequently, following the next application of red ink onto the serrations of the knife, it was struck at the abdominal integuments near the navel and as the serrated area of its upper edge touched the integuments the knife was moved tangentially to the integuments along a distance of approximately $3 \mathrm{~cm}$, achieving the effect seen in Fig. $3 \mathrm{~b}$. Then, the above action was repeated by striking the abdominal integuments with the serrated lower edge of the knife, achieving the effect illustrated in Fig. 3c.

\section{Results and discussion}

A comparison of the morphological features of the stab wound of the abdomen found during XY's autopsy (Fig. 2a) and the morphological features of the wound of the abdomen resulting from the above experiment (Fig. 2b) showed a similarity between their shapes and the location and size of the linear skin abrasions in the edges of both wounds. What particularly weighed in favor of their origin in the same instrument was the identical width of the abrasions $(0.1 \mathrm{~cm})$ and the distance between them $(0.2 \mathrm{~cm})$. This shows that the characteristic striated abrasion of the skin near the wound in the abdominal integuments found during the autopsy could have resulted from the contact of the integuments in the immediate vicinity of the wound with the serrations of the depression at the border of the blade and the hilt of the seized knife located on the lower (blade) side. Hence, the outcome of the experiment suggests that the characteristic damage found in the vicinity of the wound most probably resulted from thrusting the knife deep into the abdomen and then rotating around its long axis to the left, simultaneously pressing the serrated edge to the abdominal integuments $[4,14]$.

A comparison of the characteristic striated skin abrasion found during XY's autopsy (Fig. 3a) and the changes resulting from the experiment with the knife constituting material evidence (Fig. $3 \mathrm{~b}$ and c) indicates that the abrasion on the abdomen near the navel found during the postmortem could have resulted from the contact of the integuments in this area of the body with the serrations located on the borderline of the knife's blade and hilt. This is clearly evidenced by the same number and width of the linear abrasions of the integuments and the distance between them - the same as for the abrasions in the edges of the wounds (Fig. 2a, b). The striated abrasion in abdominal skin resulted from the tangential action of the above-described serrations on the knife on the abdominal integuments and it could have originated from the action of the serrations located both on the lower and upper edge of the knife seized as material evidence.

\section{Conclusions}

The experiment using the material evidence, conducted at the public prosecutor's order, led to the assumption that the injuries found during the autopsy could have originated from the action of the seized knife. The experiment demonstrated that the striated marks found in the integuments of the body, at first glance suggesting their possible origin in a serrated knife blade, actually originated from the decorative rather than functional serrations discreetly located near the hilt of a knife with a smooth blade. Such conclusions could not be drawn in a different way, e.g., based exclusively on a comparison between the appearance and features of the knife and the injuries to the body integuments. Thus, the present paper points to the usefulness of experiments using material evidence, such as alleged instruments of crime, to identify the origin of bodily injuries, if the need arises.

Open Access This article is distributed under the terms of the Creative Commons Attribution Noncommercial License which permits any noncommercial use, distribution, and reproduction in any medium, provided the original author(s) and source are credited.

\section{References}

1. Kettner M, Gade G, Ramsthaler F, Shah S, Pape A, Theisen A, Schmidt P (2010) Experimental studies on the wounding capacity of recently developed shuriken/throwing stars and their legal categorization - an interdisciplinary view. Arch Kriminol 225:167-180 
2. Hainsworth SV, Delaney RJ, Rutty GN (2008) How sharp is sharp? Towards quantification of the sharpness and penetration ability of kitchen knives used in stabbings. Int J Legal Med 122:281-291

3. Pollak S (1989) Pattern of findings in injuries caused by "survival knives". Arch Kriminol 183:11-20

4. Pollak S, Fischer A (1991) Morphometric findings of stab wounds. Beitr Gerichtl Med 49:219-225

5. Daeid NN, Cassidy M, McHugh S (2008) An investigation into the correlation of knife damage in clothing and the lengths of skin wounds. Forensic Sci Int 179:107-110

6. Sitiene R, Zakaras A, Pauliukevicius A, Kisielius G (2007) Morphologic, experimental-comparative investigation as an identification of the injuring instrument method. Forensic Sci Int 167:255-260

7. Pollak S, La Harpe R (1992) Defined contusion marks caused by the knife handle. Arch Kriminol 190:1-8

8. Große Perdekamp M, Max A, Merkel J, Mierdel K, Braunwarth R, Kneubuehl BP, Pollak S, Thierauf A (2011) GSR deposition along the bullet path in contact shots to composite models. Int J Legal Med 125:67-73
9. Große Perdekamp M, Nadjem H, Merkel J, Braunwarth R, Pollak S, Thierauf A (2011) Two-gun suicide by simultaneous shots to the head: interdisciplinary reconstruction on the basis of scene investigation, autopsy findings, GSR analysis and examination of firearms, bullets and cartilage cases. Int J Legal Med. doi:10.1007/ s00414-010-0517-6

10. Pounder DJ, Reeder FD (2010) Striation patterns in serrated blade stabs to cartilage. Forensic Sci Int. doi:10.1016/j.forsciint.2010.11.015

11. Thompson TJU, Inglis J (2009) Differentiation of serrated and non-serrated blades from stab marks in bone. Int $\mathrm{J}$ Legal Med 123:129-135

12. Sperry K, Campbell HR (1990) An elliptical incised wound of the breast misinterpreted as a bite injury. J Forensic Sci 35:1226-1235

13. Carr DJ, Wainwright A (2011) Variability of simulants used in recreating stab events. Forensic Sci Int. doi:10.1016/j.for sciint.2011.01.032

14. Karlsson T (1998) Multivariate analysis ('forensiometrics') - a new tool in forensic medicine. Differentiation between sharp force homicide and suicide. Forensic Sci Int 94:183-200 